\title{
Treatment of posttraumatic stress disorder following childbirth
}

\section{Lisa de Bruijn, Claire A. Stramrood, Mijke P. Lambregtse-van den Berg \&} Nathaly Rius Ottenheim

To cite this article: Lisa de Bruijn, Claire A. Stramrood, Mijke P. Lambregtse-van den Berg \& Nathaly Rius Ottenheim (2019): Treatment of posttraumatic stress disorder following childbirth, Journal of Psychosomatic Obstetrics \& Gynecology, DOI: 10.1080/0167482X.2019.1593961

To link to this article: https://doi.org/10.1080/0167482X.2019.1593961

\section{舟 Published online: 04 Jun 2019.}

Submit your article to this journal $₫$

Џ Article views: 56

View Crossmark data ¿ 


\title{
Treatment of posttraumatic stress disorder following childbirth
}

\author{
Lisa de, Bruijn ${ }^{a}$, Claire A. Stramrood ${ }^{b}$, Mijke P. Lambregtse-van den Berg ${ }^{c, d}$ and Nathaly Rius Ottenheim ${ }^{e}$

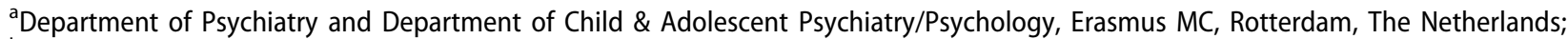 \\ bepartment of Obstetrics and Gynaecology, Amsterdam UMC, Amsterdam, the Netherlands; 'Department of Psychiatry, Erasmus MC, \\ Rotterdam, The Netherlands; ${ }^{\mathrm{d} D e p a r t m e n t}$ of Child \& Adolescent Psychiatry/Psychology, Erasmus MC, Rotterdam, The Netherlands; \\ e Department of Psychiatry, Leiden University Medical Center, Leiden, the Netherlands
}

ABSTRACT

Aim: The aim of this systematic review is to give an overview of the literature on treatment options for posttraumatic stress disorder (PTSD) following childbirth and to assess their efficacy. Method: PubMed, Embase, Web of Science, Cochrane and PsycINFO were searched using "PTSD", "childbirth" and "therapy" as terms for studies in English language published between 2000 and 2017. Additional studies were identified by checking reference lists. Studies were included when presence of PTSD was confirmed prior to treatment and childbirth was the traumatic event focused on. All studies were reviewed on sample size, study design, used instruments, sample characteristics, type of treatment and the result of treatment regarding PTSD (symptoms).

Results: Six studies met the inclusion criteria. One study on debriefing, three studies on cognitive behavioral therapy (CBT) and two studies on eye movement desensitization and reprocessing (EMDR) were identified. Both EMDR and CBT appear to be promising therapies for PTSD following childbirth. Debriefing seems to be beneficial when women request it themselves.

Conclusions: EMDR and CBT seem to be effective as therapy for PTSD following childbirth. However, evidence is still limited and more controlled trials are needed to draw conclusive results.
ARTICLE HISTORY

Received 4 January 2018

Revised 20 February 2019

Accepted 8 March 2019

KEYWORDS

PTSD following childbirth; treatment; EMDR; CBT; debriefing

\section{Introduction}

Pregnancy and childbirth are usually considered to be positive events. However, for some women, childbirth and the following puerperal period are complicated due to mental health problems. As a result of extensive research, postpartum depression and psychosis are nowadays well-known mental health problems among the population and clinicians [1]. This is not yet the case for posttraumatic stress disorder (PTSD) following childbirth [2]. A growing body of evidence suggests that giving birth may be experienced as a traumatic event and lead to PTSD [3,4]. People may develop PTSD after experiencing an event which is traumatic, such as threatened death, serious injury or sexual violation [5]. PTSD is characterized by symptoms of re-experiencing, avoidance, negative cognitions and mood, and hyperarousal. These symptoms must be present for more than one month [5]. Avoidance and re-experiencing appear to be the most outspoken symptoms in women suffering from PTSD following childbirth [6]. A recent meta-analysis found that $4.0 \%$ of women develop PTSD following childbirth [7]. A higher prevalence of PTSD has been found in women with complications in pregnancy and during delivery [8-11]. The overall prevalence in these highrisk samples was $15.7 \%$ [10].

PTSD following childbirth has serious consequences for a number of daily life aspects [12]. Women suffering from PTSD following childbirth often feel misunderstood and not supported by their families because their relational context considers childbirth as a positive event [13]. Furthermore, PTSD following childbirth may have negative effects on the relationship with the partner, including negative emotions and poor communication, decreased intimacy, sexual dysfunction and even separation $[14,15]$. Women may avoid sexual engagement out of fear of becoming pregnant again $[16,17]$. If they do become pregnant, they may avoid having antenatal check-ups with a midwife or an obstetrician $[11,18]$. In addition, women may suffer from severe anxiety before or during subsequent delivery, which is associated with more elective and emergency cesarean sections $[15,19,20]$. 
PTSD following childbirth may also affect the mother-baby bond [14]. The majority of women reports initial feelings of rejection toward their baby and experiencing difficulties to develop a bond with their child $[3,13,16,21,22]$. On the long-term, this group of women shows suboptimal bonding with their child, such as avoidant or anxious bonds $[14,15]$.

A recent systematic review identified the most relevant risk factors for developing PTSD following childbirth [23]. Most strongly associated pre-birth risk factors are having a history of psychopathology, especially a history of PTSD, anxiety disorder or depression; complications in pregnancy, depression in pregnancy and fear of childbirth. During birth, the identified risk factors include negative subjective experiences, such as negative emotions during birth and experiencing lack of control [10,23-25]. Also, contributing to a negative experience is lack of support by partner and medical staff, which are identified separately as strongly associated risk factors [6,26-28]. A positive correlation between operative deliveries and presence of PTSD was found [23]. Complications with the infant during delivery are also a strong predictor of PTSD following childbirth $[8,29,30]$. After birth, poor coping and stress, and depression are identified as risk factors $[3,10,23]$.

Knowledge of prevalence and risk factors is relevant to develop effective treatment programs. Treatment for non-childbirth related PTSD includes debriefing, cognitive behavior therapy (CBT) and eye movement desensitization and reprocessing (EMDR) [31,32]. Debriefing is defined as a semi-structured conversation in order to reduce the possibility of psychological damage and pursuing recovery after a traumatic event. A structured procedure, the critical incident stress debriefing, was developed by Mitchell in 1983 and became a widely used therapeutic intervention [33]. The way in which debriefing is most often being used in the postpartum period has, however, an unstructured approach and focuses on providing the women an opportunity to talk about her feelings and emotions involving her delivery [22]. CBT is a form of psychotherapy in which negative cognitions about the self and the world are challenged in order to alter unwanted beliefs and behavior patterns. EMDR is a protocolled technique whereby the therapist asks the participant to focus on the traumatic events and the associated emotions, while engaging in bilateral stimulation with eye movements [34]. CBT and EMDR are most commonly used as therapy since research has confirmed their efficacy [31,32]. Results on debriefing as possible therapy remain inconclusive $[22,25,35]$.
Taken together, the consequences of posttraumatic symptoms after childbirth are serious. Therefore, it is important that adequate therapeutic interventions are developed to treat women with PTSD following childbirth. In order to provide directions for further research to this review will present an overview of the literature up to May 2017 on the existing treatment options and will assess their efficacy.

\section{Method}

In order to gather studies for this review on treatment of PTSD following childbirth, PubMed, Embase Web of Science, Cochrane and PsycINFO were searched for studies in English language with a combination of PTSD terms (posttraumatic stress disorder and PTSD), childbirth terms (childbirth, parturition, labor, obstetric delivery, cesarean birth, birth, puerperium, postpartum, postpartal and postnatal) and therapy terms (treatment, therapy, disease management, and crisis intervention). The search result showed no pharmacological studies. Three types of therapeutic interventions were found: debriefing, CBT and EMDR. More studies were searched by adding the three types of therapy separately. Duplicates were removed by using EndNote X7. The reference lists of all studies were checked to identify other studies of importance.

Two authors (NR and LB) first screened 638 titles and abstracts to include or exclude relevant studies. Subsequently, when sufficient information was lacking in the abstracts, full text articles were reviewed by the same reviewers. Twenty-one full text articles were reviewed. A total of six studies met the inclusion criteria.

The studies included were published until May 2017 and written in the English language. To be included, the studies had to be empirical research with confirmation of presence of PTSD prior to start of the treatment. The presence of PTSD had to be measured by using qualitative or quantitative methods. Furthermore, childbirth had to be more than one month ago and it had to be the traumatic event therapy focused on. Studies also had to report the type of treatment and the result on PTSD symptoms after treatment. Vaginal births as well as operative births were included. Conference abstracts, editorial comments and reviews were excluded. In addition, studies concerning spontaneous abortion, miscarriage, stillbirth or traumatic experiences at the neonatal intensive care unit (NICU) in parents with pre-term born babies were excluded. Also, studies reporting on 
prevention of developing PTSD following childbirth were excluded.

One author (LB) extracted the following data from all included studies: country, study design, in- and exclusion criteria, sample characteristics, type of treatment, the result of the treatment regarding PTSD (symptoms) and risk of bias by using the Cochrane Risk of Bias Tool.

\section{Results}

Six studies met the inclusion criteria $[13,16,17,36-38]$. The result of the search is shown in Figure 1. All studies focused on childbirth as the traumatic event and confirmed validated presence of PTSD prior to start of treatment. Studies were conducted between 2003 and 2016. Of the included studies, two studies were conducted as pilot study, two as case series and two as controlled trials. One study evaluated debriefing, three studies CBT and two studies EMDR.
All studies included in the review are presented in Table 1.

\section{Debriefing}

One study investigated post-partum debriefing (also known as postnatal debriefing) as therapy for posttraumatic symptoms following childbirth [36]. This non-randomized controlled trial was performed with 46 women that requested debriefing. The debriefing session was given at a broad range of time after delivery. The control group consisted of 34 women who did not want debriefing. In both the intervention and the control group, all women met criterion A of the DSM-IV classification of PTSD. One individual debriefing session was given by a midwife with specialist training in counseling techniques or cognitive behavior techniques and solution focused therapy. The effect of the debriefing session was measured immediately after session and after one month. Even though there was a significant effect of time on symptom

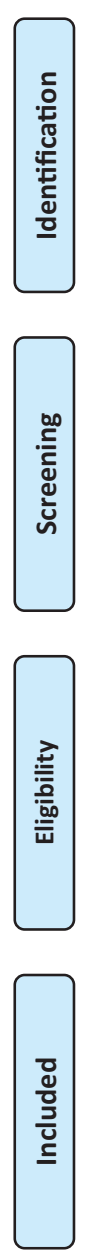

Records identified through database searching

PubMed: $(n=465)$

Embase: $(n=226)$

Web of science: $(n=45)$

Cochrane: $(n=14)$

PsycINFO: $(n=31)$
Additional records identified

through other sources

$(n=8)$

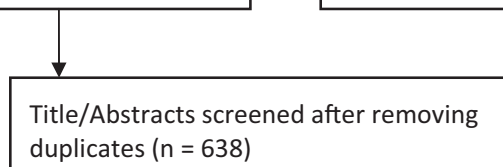

duplicates $(n=638)$
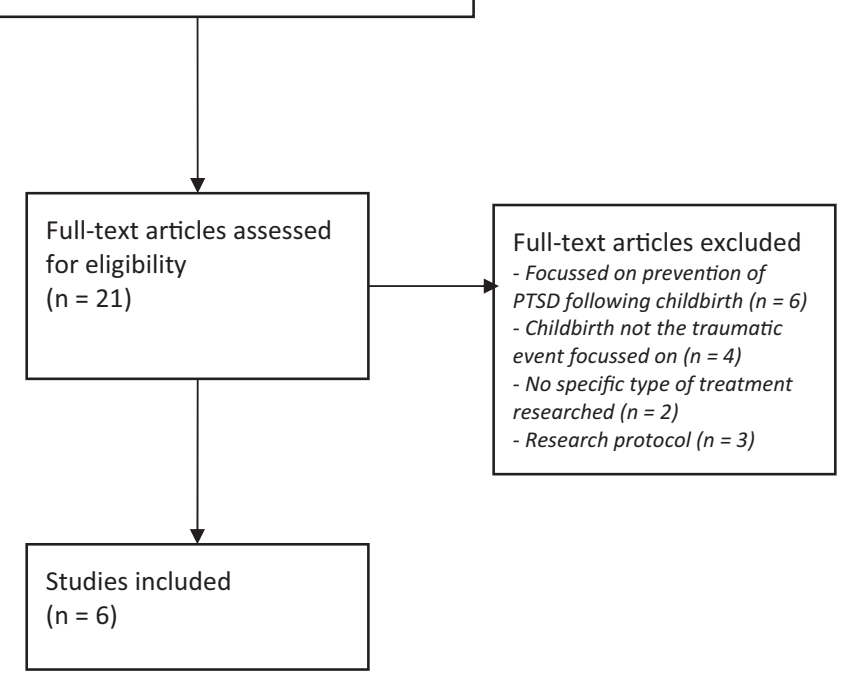

Figure 1. Flow chart of systematic search. 


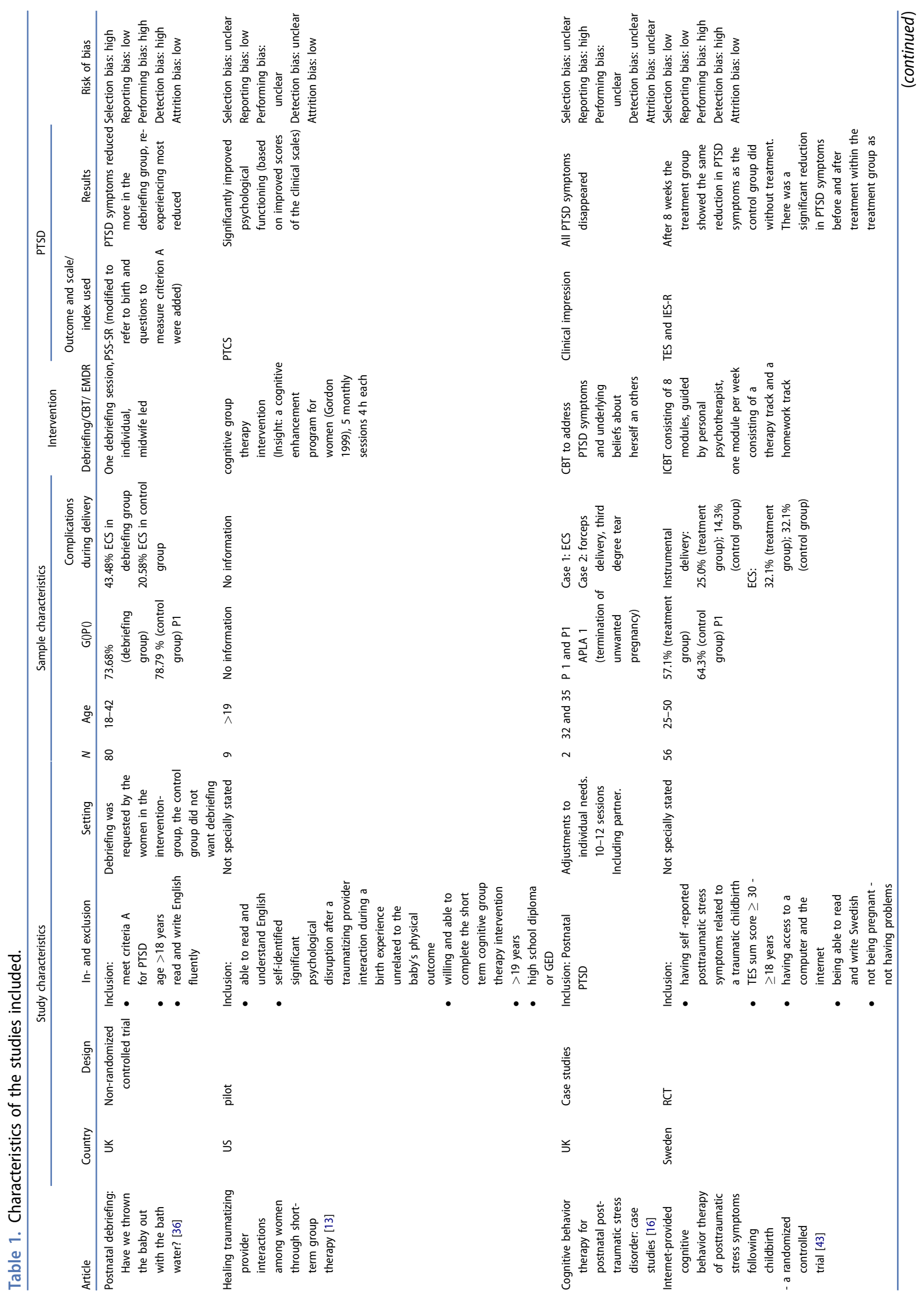


JOURNAL OF PSYCHOSOMATIC OBSTETRICS \& GYNECOLOGY $\rightarrow 5$

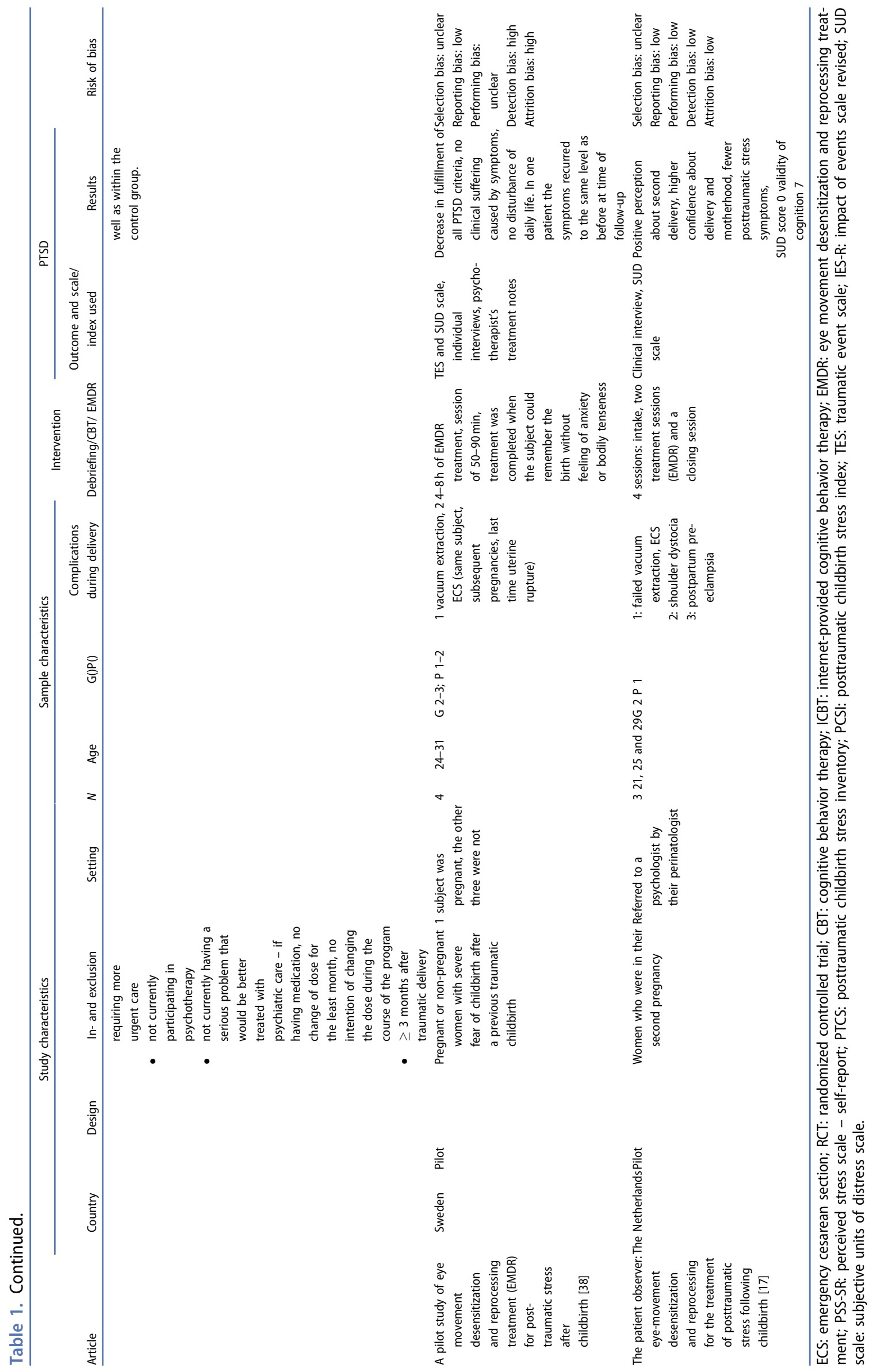


reduction in both groups, the results showed a greater reduction in PTSD symptoms in the debriefing group.

\section{Cognitive behavioral therapy (CBT)}

Three studies explored CBT as possible therapy for PTSD following childbirth $[13,16,37]$.

The first study, by Sorenson, was a pilot study conducted among nine women who met the diagnostic criteria for PTSD. The study explored the possibility of a short-term cognitive group therapy following Gordon's intervention: "Insight: A cognitive enhancement program for women, facilitator's manual" [39]. Participants were divided into groups of four to five women. All received five monthly sessions of 4 hours each, during which they were stimulated to challenge their cognitions, received feedback, and were able to grow into new coping strategies. After treatment, the PTSD symptoms were significantly reduced.

The second study, by Ayers et al. [16], explored the feasibility of CBT as treatment in an individual setting. Two cases were described of women suffering from a clinically confirmed PTSD following childbirth; one for who fear was the dominant feeling and the second for whom anger and guilt were the dominant feelings. The two women had given birth 8 and 14 months before the start of the study. Both had delivered by emergency cesarean section. In the second case, forceps delivery was unsuccessful and emergency cesarean section was performed afterward. Both received therapy individually and, therefore, therapy could be adjusted to their specific symptoms. In the second case, the partner became involved in therapy. The first case received 10 sessions, whilst the second case received 12 treatment sessions. After the sessions, all PTSD symptoms had disappeared in both women.
The third study, by Nieminen et al. was a randomized controlled trial among 43 women, which looked into the feasibility of internet-provided cognitive behavior therapy. All women reported posttraumatic stress symptoms related to their delivery more than three months ago. Women were included when they had a score on the Traumatic Event Scale (TES) [40] over 30 points. Participants were divided into a group that received immediate treatment and a group put on a waiting list (control group), which would receive treatment five months later. The treatment group constituted of 24 women and the control group 19 women. The treatment consisted of eight online modules, each with a therapy track and a homework track. The women were guided by a personal psychotherapist. After 8 weeks the treatment group showed the same reduction in PTSD symptoms as the control group did without treatment. However, there was a significant reduction in PTSD symptoms before and after treatment within the treatment group as well as within the control group.

\section{Eye movement desensitization and reprocessing treatment (EMDR)}

Two studies described EMDR as possible treatment for PTSD following childbirth $[17,38]$. The EMDR sessions given in both studies were according to the structured treatment package as developed by Shapiro (Table 2) [34].

The first study was a pilot study with a pre-posttest design in four women of which one was pregnant [38]. The first subject had two previous pregnancies which both ended by emergency cesarean section. The other participants had given birth vaginally, although one delivery was performed with vacuum extraction due to maternal exhaustion. All the

Table 2. EMDR structured treatment package by Shapiro.

Stage
$\begin{aligned} & \text { Explanation of procedure, assessment of past and current medical status and the presenting problem } \\ & \text { 1. Preparation } \\ & \text { 2. Assessment }\end{aligned}$
$\begin{aligned} & \text { The patient visualizes the most disturbing moment from the traumatic event and formulates a negative cognition about herself } \\ & \text { related to the traumatic event. Subsequently she formulates an alternative positive cognition and rates this cognition. Then } \\ & \text { the patient describes her feelings that are associated with the traumatic event and rates the disturbance on the SUD scale } \\ & \text { The patient will concentrate on the traumatic event and scan her entire body for physical sensations } \\ & \text { 3hile focusing on the experiencing distress, bilateral stimulations are given by the psychotherapist by moving the hand back } \\ & \text { and forth in front of the face of the patient, who is following the movement of the hand with her eyes. Then, the patient is } \\ & \text { asked to speak about what thoughts or feelings come to mind. Sets of bilateral stimulations are given until the patient is } \\ & \text { repeating the same thoughts and feelings and the SUD is at the lowest possible level } \\ & \text { The patient is then asked to combine the positive cognition with the traumatic event and rate the cognition again. Sets of } \\ & \text { bilateral stimulations are given until the relationship between the positive cognition and the traumatic event has } \\ & \text { strengthened and the positive cognition is experienced as valid } \\ & \text { Again, the patient will scan her body for trauma-related physical sensations. If sensations are reported, short sets of bilateral } \\ & \text { stimulation are given until the sensations decrease or a positive feeling is experienced } \\ & \text { Explanation about session, guidance on dealing with uncomfortable feelings. Evaluation of the session is made during the } \\ & \text { following session }\end{aligned}$
$\begin{aligned} & \text { 6. Installation } \\ & \text { 7. Closure }\end{aligned}$

SUD scale: subjective units of distress scale. 
information was gathered through self-report questionnaires and therapist notes four months after the last treatment and before and after childbirth. Treatment was considered successful when the woman could look back on the childbirth without experiencing feelings of anxiety or bodily tenseness. Two women did not complete their treatment: one woman quit because she became pregnant during the study; the other quit because she disliked treatment that would make her anxiety level rise prior to improving her complaints. She was the only of the four participants that had not benefit from treatment. She reported recurrence of the same level of symptoms as prior to treatment. The level of PTSD symptoms of the other three women decreased.

The second study covered a series of three cases with women suffering from PTSD [17]. The three women included were pregnant with their second child. All perceived their first delivery as traumatic. The treatment consisted of four sessions: intake, two treatment sessions and a closing session. No validated instrument was used to measure the amount and level of PTSD symptoms. All women reported fewer symptoms after treatment and were able to look back positively on the delivery they had after treatment. They all stated that treatment contributed to their positive delivery experience.

Currently, two ongoing randomized controlled trials are assessing EMDR therapy as treatment for PTSD following childbirth. George et al. intend to assess the efficacy of EMDR after a traumatic childbirth and to determine the optimal time postpartum to start the EMDR therapy [41]. Baas et al. aim to assess the efficacy and safety of EMDR during pregnancy in women with PTSD following a previous childbirth or women with fear of childbirth [42].

\section{Discussion}

The aim of this review was to provide an overview of the literature on treatment options for PTSD following childbirth and to assess their efficacy. The result of the literature search shows three types of treatment options for PTSD following childbirth: debriefing, CBT and EMDR. After reviewing the included studies, EMDR and CBT might be effective as therapy for PTSD following childbirth.

The strength of this review is its focus precisely on studies conducted among women with PTSD symptoms as a consequence of traumatic delivery and determination thereof prior to start of treatment in all included studies. The methodology adhered to the PRISMA-guidelines.

However, this review article is not without limitations. First, this review may be affected by publication bias due to the restrictions in language and publication date. All studies reviewed have been conducted in Western, high-income countries and all the participating women delivered in hospitals, making it difficult to use the implications of this review in another setting. The largest restriction to draw solid conclusions is the lack of good quality research. The available research is scarce and of the available studies, two studies were conducted as a pilot study [13,38], two were case studies [16,17] and two were controlled trials $[36,43]$. The maximum sample size was only 80 women. The only study that performed a power calculation was the study of Nieminen et al., but the number of participants needed for an $80 \%$ power was not achieved.

Concept bias may affect this review because the studies have used different methods to indicate the presence of PTSD in their participants. Two studies used the TES [40] to measure PTSD symptoms [38,43]. Two studies measured PTSD symptoms qualitatively without making use of validated instruments, like structured clinical interviews $[16,17]$. Also used were the Perceived Stress Scale - self-report (PSS - SR) $[36,44]$, the Posttraumatic Childbirth Stress Inventory (PTCS) [13] and the Impact of Events Scale - Revised (IES - R) $[43,45]$. Some self-report questionnaires show deficits in measuring all the PTSD criteria according to the DSM-5 [31]. The IES-R and the PSS-SR do not test criterion $A$ and $F$ [25]. Meades et al. indicated in their article that they had modified the PSS-SR in order to make it fit for measurement of PTSD following childbirth, although this was not clearly specified.

The risk of bias of the individual studies was hard to determine due to lack of information in several studies on many of the criteria in the Cochrane Risk of Bias Tool. Furthermore, many studies were not conducted as an RCT, which made the risk of selection bias high, because blinding was simply not done. Most studies described their methods and incomplete data extensively, making the risk of attrition bias low.

\section{Implications for practice}

Some PTSD symptoms, like hyperarousal and sleep disorders are part of "normal" behavior after childbirth $[2,18]$. Therefore, women may not recognize their childbirth as traumatic event, since childbirth is viewed by society as a positive event [24]. In today's 
practice, many women do not mention their symptoms until a next pregnancy. Treatment is then often postponed because of fear of negative side effects for mother and fetus.

Debriefing is studied previously as prophylactic after traumatic birth to prevent women from getting PTSD. Meades has studied the possibility of debriefing as treatment for PTSD following childbirth. There are no studies that look into the possibility of debriefing as prevention for or treatment of PTSD during pregnancy. This might be because debriefing is not recommended for treatment of PTSD after other events [18].

Most guidelines recommend EMDR and CBT, which include exposure that might lead to hyperarousal, as the two preferred and most effective treatment options for PTSD. Extant findings on CBT during pregnancy for anxiety disorders also contribute to the view that exposure therapy is likely to be safe during pregnancy [46]. That CBT is the therapy of choice for PTSD forms the basis of the exploring study by Ayers et al. The authors suggest CBT might be an effective treatment when tailored to the woman's individual issues [16]. EMDR is also thought to evoke hyperarousal, which makes some clinicians to recommend caution [34], although this rationale is not evidence based. Some therapists do treat pregnant women, with a stable pregnancy and permission of their physician. For these women, the benefits for maternal quality of life and reduced stress for the developing fetus after treatment weigh up against a possible and hypothetical adverse effect of EMDR during pregnancy [47].

In this review, the study by Sandstrom et al. and the study Stramrood et al. challenge the view not to treat pregnant women with EMDR. The results from the study by Sandstrom et al. show a decrease in PTSD symptoms in three of four participants after EMDR. In the study by Stramrood et al., all women report to benefit from EMDR treatment while being pregnant and even though all their subsequent deliveries were complicated, they report to look back positively on them. The recently started trial by Baas et al. will challenge Shapiro's view even further by conducting their research on EMDR as therapy in a population consisting of 50 pregnant women.

Taken together, this review stresses the importance of training clinicians in recognizing PTSD following childbirth and its risk factors. Due to the relatively high prevalence, especially in high-risk samples, and the serious consequences of PTSD following childbirth, obstetric care providers must be made aware of this condition. Grekin and O'Hara argue in favor of a distinction between women who identify their childbirth as traumatic due to unexpected interventions and women who already possess vulnerability due to prior trauma.

When staff is trained in recognizing PTSD, they are able to point out symptoms in women who are unaware of the existence of PTSD following childbirth and direct these women to further help. It would be beneficial to discuss the woman's experience of the childbirth during the standard postpartum check with the midwife or obstetrician, usually at one to two months postpartum. This moment could be used to perform a first screening on PTSD and refer for further treatment. A following contact with high-risk patients and patient with a high score during the first screening to evaluate a decrease of the symptoms could be three months after childbirth, since spontaneous remission of PTSD is unlikely beyond three months [18]. Furthermore, at six months postpartum the prevalence of PTSD following childbirth is higher in comparison to the prevalence at three months postpartum [7]. Contact and possible treatment at three months postpartum may prevent symptoms to increase or to first become apparent during a subsequent pregnancy.

For women who appear to be more vulnerable for PTSD after childbirth, because of a previous traumatic experience, a history of mental health problems or fear of childbirth, clinical guidelines with preventive measures should be developed. Thus far, research on prevention of traumatic delivery experiences and PTSD following childbirth is scarce, and no intervention has been proven to be very effective [48].

\section{Implications for research}

Some researchers indicate that adjusting existing selfreport questionnaires for PTSD to women with newborn babies may strengthen the validity. For example, when exploring sleep difficulties, a phrase such as "not due to being woken by my baby" could be added $[3,10,24]$. In 2010, Stramrood et al. formulated the contents for an "ideal" self-report instrument. According to their qualitative analysis criterion $A$ and all the symptoms clusters should be explored on intensity. The cut-off value should be two or more on a four-point scale, ranging from zero to three. None of the symptoms should be present before delivery [49]. The TES is yet the only questionnaire that constitutes these contents. However, the TES is not validated for PTSD following childbirth. 
Furthermore, since only one study is available on postpartum debriefing as treatment, it is recommended to extend and verify its findings. What needs to be examined more thoroughly is which elements make postpartum debriefing suitable for treatment and which make it suitable as prevention, for which debriefing is most widely used.

Randomized controlled trials on CBT and EMDR should be conducted before solid conclusions can be drawn about effectiveness of CBT and EMDR as therapy for PTSD following childbirth. One RCT on CBT has been conducted with a too small sample size to reach a power of $80 \%$ [43]. Longitudinal studies could shed light on whether CBT and EMDR have an enduring effect and thereby can protect a woman from PTSD symptoms during her following childbirth.

\section{Conclusion}

This review aimed to assess the available treatment options for PTSD following childbirth. Three options are available as treatment for PTSD following childbirth: debriefing, CBT and EMDR. From the six studies included could be concluded that postpartum debriefing appears to be beneficial for women requesting debriefing themselves. Second, studies on CBT and EMDR show a significant reduction in PTSD symptoms, even though research is limited. In order to draw solid conclusions about the efficacy of these three treatment options good quality research, such as RCT's, is necessary.

\section{Acknowledgments}

The authors would like to thank J. van Hoorn, PhD, J. Kamilic, PhD, and D.C. Eindhoven, PhD, for their helpful comments. Furthermore, the authors would like to thank J.W. Schoones, Drs, for his assistance performing the literature search.

\section{Disclosure statement}

Not the authors nor Mr Schoones, Ms van Hoorn, Ms Kamilic and Ms Eindhoven have a conflict of interest to declare.

\section{References}

[1] Ayers S. Fear of childbirth, postnatal post-traumatic stress disorder and midwifery care. Midwifery. 2014; 30:145-148.

[2] McKenzie-McHarg K, Ayers S, Ford E, et al. Post-traumatic stress disorder following childbirth: an update of current issues and recommendations for future research. J Reprod Infant Psychol. 2015;33:219-237.
[3] Andersen LB, Melvaer LB, Videbech P, et al. Risk factors for developing post-traumatic stress disorder following childbirth: a systematic review. Acta Obstet Gynecol Scand. 2012;91:1261-1272.

[4] Soderquist J, Wijma B, Thorbert G, et al. Risk factors in pregnancy for post-traumatic stress and depression after childbirth. BJOG. 2009;116:672-680.

[5] American Psychiatric Association. Diagnostic and statistical manual of mental disorders. 5th ed. Arlington (VA): American Psychiatric Publishing; 2013.

[6] Czarnocka J, Slade P. Prevalence and predictors of post-traumatic stress symptoms following childbirth. Br J Clin Psychol. 2000;39:35-51.

[7] Yildiz PD, Ayers S, Phillips L. The prevalence of posttraumatic stress disorder in pregnancy and after birth: a systematic review and meta-analysis. J Affect Disord. 2017;208:634-645.

[8] Engelhard IM, van Rij M, Boullart I, et al. Posttraumatic stress disorder after pre-eclampsia: an exploratory study. Gen Hosp Psychiatry. 2002;24: 260-264.

[9] Furuta M, Sandall J, Bick D. A systematic review of the relationship between severe maternal morbidity and post-traumatic stress disorder. BMC Pregnancy Childbirth. 2012;12:125.

[10] Grekin R, O'Hara MW. Prevalence and risk factors of postpartum posttraumatic stress disorder: a meta-analysis. Clin Psychol Rev. 2014;34:389-401.

[11] Stramrood CA, Wessel I, Doornbos B, et al. Posttraumatic stress disorder following preeclampsia and PPROM: a prospective study with 15 months follow-up. Reprod Sci. 2011;18:645-653.

[12] Kessler RC. Posttraumatic stress disorder: the burden to the individual and to society. J Clin Psychiatry. 2000;61(5): 4-12.

[13] Sorenson DS. Healing traumatizing provider interactions among women through short-term group therapy. Arch Psychiatr Nurs. 2003;17:259-269.

[14] Ayers S, Eagle A, Waring $H$. The effects of childbirthrelated post-traumatic stress disorder on women and their relationships: a qualitative study. Psychol Health Med. 2006;11:389-398.

[15] Nicholls K, Ayers S. Childbirth-related post-traumatic stress disorder in couples: a qualitative study. $\mathrm{Br} \mathrm{J}$ Health Psychol. 2007;12:491-509.

[16] Ayers S, McKenzie-McHarg K, Eagle A. Cognitive behaviour therapy for postnatal post-traumatic stress disorder: case studies. J Psychosom Obstet Gynecol. 2007;28:177-184.

[17] Stramrood CA, van der Velde J, Doornbos B, et al. The patient observer: eye-movement desensitization and reprocessing for the treatment of posttraumatic stress following childbirth. Birth. 2012;39:70-76.

[18] Ayers S, Joseph S, McKenzie-McHarg K, et al. Posttraumatic stress disorder following childbirth: current issues and recommendations for future research. J Psychosom Obstet Gynecol. 2008;29:240-250.

[19] Hofberg K, Brockington I. Tokophobia: an unreasoning dread of childbirth. A series of 26 cases. $\mathrm{Br} J$ Psychiatry. 2000;176:83-85.

[20] Laursen M, Johansen C, Hedegaard M. Fear of childbirth and risk for birth complications in nulliparous 
women in the Danish National Birth Cohort. BJOG. 2009;116:1350-1355.

[21] Ayers S, Pickering AD. Do women get posttraumatic stress disorder as a result of childbirth? A prospective study of incidence. Birth. 2001;28:111-118.

[22] Bastos $M H$, Furuta $M$, Small $R$, et al. Debriefing interventions for the prevention of psychological trauma in women following childbirth. Cochrane Database Syst Rev. 2015;CD007194.

[23] Ayers S, Bond R, Bertullies S, et al. The aetiology of post-traumatic stress following childbirth: a metaanalysis and theoretical framework. Psychol Med. 2016:46:1121-1134.

[24] Ayers S. Delivery as a traumatic event: prevalence, risk factors, and treatment for postnatal posttraumatic stress disorder. Clin Obstet Gynecol. 2004;47:552-567.

[25] Olde E, Van Der Hart O, Kleber R, et al. Posttraumatic stress following childbirth: a review. Clin Psychol Rev. 2006;26:1-16.

[26] Cigoli V, Gilli G, Saita E. Relational factors in psychopathological responses to childbirth. J Psychosom Obstet Gynaecol. 2006;27:91-97.

[27] Soderquist J, Wijma B, Wijma K. The longitudinal course of post-traumatic stress after childbirth. J Psychosom Obstet Gynaecol. 2006;27:113-119.

[28] Soet JE, Brack GA, Dilorio C. Prevalence and predictors of women's experience of psychological trauma during childbirth. Birth. 2003;30:36-46.

[29] Fairbrother N, Woody SR. Fear of childbirth and obstetrical events as predictors of postnatal symptoms of depression and post-traumatic stress disorder. J Psychosom Obstet Gynaecol. 2007;28: 239-242.

[30] Feeley N, Zelkowitz P, Cormier C, et al. Posttraumatic stress among mothers of very low birthweight infants at 6 months after discharge from the neonatal intensive care unit. Appl Nurs Res. 2011;24:114-117.

[31] American Psychiatric Association. Practice guideline for the treatment of patients with acute stress disorder and posttraumatic stress disorder. Arlington (VA): American Psychiatric Association Practice Guidelines; 2013

[32] Trimbos Instituut. Multidisciplinaire richtlijn angststoornissen, derde revisie. Utrecht, Netherlands: Trimbos Instituut; 2013.

[33] Mitchell JT. When disaster strikes ... the critical incident stress debriefing process. JEMS. 1983;8:36-39.

[34] Shapiro F. Eye movement desensitization and reprocessing. Basic principles, protocols, and procedures. 2nd ed. New York (NY): Guilford Press; 2001.

[35] Lapp LK, Agbokou C, Peretti CS, et al. Management of post traumatic stress disorder after childbirth: a review. J Obst Gynecol. 2010;31:113-122.
[36] Meades R, Pond C, Ayers S, et al. Postnatal debriefing: have we thrown the baby out with the bath water? Behav Res Ther. 2011;49:367-372.

[37] Nieminen K, Andersson G, Wijma B, et al. Treatment of nulliparous women with severe fear of childbirth via the internet: a feasibility study. J Psychosom Obstet Gynecol. 2016;37:37-43.

[38] Sandstrom M, Wiberg B, Wikman $M$, et al. A pilot study of eye movement desensitisation and reprocessing treatment (EMDR) for post-traumatic stress after childbirth. Midwifery. 2008;24:62-73.

[39] Gordon VS. Insight: a cognitive enhancement program for women. Minneapolis (MN): Author; 1999.

[40] Wijma K, Soderquist J, Wijma B. Posttraumatic stress disorder after childbirth: a cross sectional study. J Anxiety Disord. 1997;11:587-597.

[41] George A, Thilly N, Rydberg JA, et al. Effectiveness of eye movement desensitization and reprocessing treatment in post-traumatic stress disorder after childbirth: a randomized controlled trial protocol. Acta Obstet Gynecol Scand. 2013;92:866-868.

[42] Baas MA, Stramrood CA, Dijksman LM, et al. The OptiMUM-study: EMDR therapy in pregnant women with posttraumatic stress disorder after previous childbirth and pregnant women with fear of childbirth: design of a multicentre randomized controlled trial. Eur J Psychotraumatol. 2017;8:1293315.

[43] Nieminen K, Berg I, Frankenstein K, et al. Internet-provided cognitive behaviour therapy of posttraumatic stress symptoms following childbirth-a randomized controlled trial. Cogn Behav Ther. 2016;45:287-306.

[44] Foa EB, Riggs DS, Dancu CV, et al. Reliability and validity of a brief instrument for assessing post-traumatic stress disorder. J Trauma Stress. 1993;6:459-473.

[45] Weiss DS, Marmar CR. Assessing psychological trauma and PTSD. New York (NY): Guilford Press; 1997. The impact of event scale-revised. p. 399-411.

[46] Arch JJ, Dimidjian S, Chessick C. Are exposure-based cognitive behavioral therapies safe during pregnancy? Arch Womens Ment Health. 2012;15:445-457.

[47] Forgash C, Leeds A, Stramrood CA, et al. Case consultation: traumatized pregnant woman. J Emdr Prac Res. 2013;7:45-49.

[48] de Graaff LF, Honig A, van Pampus MG, et al. Preventing post-traumatic stress disorder following childbirth and traumatic birth experiences: a systematic review. Acta Obstet Gynecol Scand. 2018;97: 648-656.

[49] Stramrood CA, Huis In 't Veld EM, Van Pampus MG, et al. Measuring posttraumatic stress following child-birth: a critical evaluation of instruments. J Psychosom Obstet Gynaecol. 2010;31:40-49. 